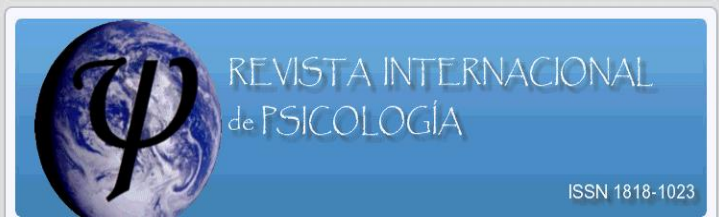

\title{
Tecnologías de la comunicación y emocionalidad en familias transnacionales
}

\section{Communication technologies and emotionality in transnational families}

\author{
Licda. María Guadalupe Ramírez Contreras \\ Universidad de Guadalajara
}

\section{Nota sobre la autora}

María Guadalupe Ramírez Contreras. Candidata a Doctor en Ciencias de la Salud Pública. Departamento de Salud Pública. Centro Universitario de Ciencias de la Salud. Universidad de Guadalajara.

Esta investigación se llevó a cabo con el apoyo económico otorgado por el Consejo Nacional de Ciencia y Tecnología (CONACYT) mediante El Programa Nacional de Posgrados de Calidad (PNPC).

Remita cualquier duda sobre este artículo al siguiente domicilio: Sierra Mojada \#950, Puerta 3, Edificio "N", Planta Alta, Depto. de Salud Pública. Correo electrónico: pikysmorgan@hotmail.com 


\section{Resumen}

En 2009, la estimación de migrantes mexicanos en Estados Unidos era 11,500.0 millones (Centro Hispánico Pew, 2009). Dichos migrantes no siempre llevan a su familia con ellos. Ante esta separación, las familias transnacionales intentan compensar la ruptura con una cercanía emocional, a través del uso de las tecnologías de comunicación. Sin embargo ¿qué tipo de apoyo emocional se da cuando un familiar de la tercera edad padece una enfermedad crónica? ¿Cómo viven la emocionalidad dichas familias transnacionales? ¿Qué tecnologías utilizan para comunicarse? y ¿Cómo se relaciona la comunicación con el apoyo emocional? Para dar respuestas busqué cubrir las carencias de estudios previos, en los que sólo incluían la perspectiva de los migrantes e incluí el punto de vista de todos los miembros de las familias. Llevé a cabo un estudio cualitativo al occidente de México. Entrevisté a diferentes miembros de 15 familias transnacionales durante el año 2012 y 2013. Los resultados mostraron que el apoyo emocional en las familias consistía en: a) el establecimiento de la comunicación iniciado por los migrantes, b) el intercambio de vivencias del día a día; c) la resolución de problemas o conflictos; y d) el acompañamiento, participación o presencia del migrante en fechas especiales. Los migrantes utilizaron las tecnologías de comunicación para mantener vínculos afectivos y dar apoyo emocional a sus padres. Dichas tecnologías también les permitieron manifestar soledad y nostalgia. Recomiendo estudiar a los migrantes nacionales y a las poblaciones rurales, para analizar si existen diferencias con las poblaciones de mi estudio.

Palabras clave: tecnologías de comunicación; migración internacional; emocionalidad; familias transnacionales 
It was estimated in 2009 that 11,500.0 millions Mexican immigrants were living in the United States (Pew Hispanic Center, 2009). However, such immigrants can't take their families with them to the US breaking-up of the family unit. Therefore, immigrants and their families become members of a transnational family. In order to cope with such family break-up, members of such families try to balance themselves through developing an emotional intimacy using communication technologies. However, what kind of emotional support is offered when one of the members of the transnational family is a senior citizen and chronically ill? What kind of emotions do these transnational families experience? Which communication technologies do they use to be in touch? How these communication technologies are related to the emotional support? In order to answer these research questions, I explored previous studies in which I found that they only included the immigrants' point of view. To overcome this limitation in this study, I included the point of view of all members of transnational families. I conducted a qualitative study. It took place in Sahuayo, Michoacan. I interviewed members of 15 transnational families during 2012 and 2013. The results showed that emotional support was identified as: a) contacting relatives in Mexico, initiated by immigrants, b) exchanging daily life experiences; c) solving issues and conflicts; and d) immigrants supporting, participating or being virtually in special celebrations. Immigrants also used communication technologies in order to maintain emotional ties and give emotional support to their parents. The communication help immigrants to provide the emotional support to their parents and also to express their feelings. I recommend studying national migrants and rural populations, in order to analyse any differences between them and my sample.

Keywords: communication technologies; migration international; emotionality; transnational families 


\section{Introducción}

El fenómeno de la migración de mexicanos a Estados Unidos de América es un tema estudiado frecuentemente. Los migrantes mexicanos en Estados Unidos conforman un grupo poblacional grande. De acuerdo a las cifras, a principios del 2009 se estimaron 11,500.0 millones de migrantes mexicanos viviendo en Estados Unidos (Centro Hispánico Pew, 2009). Sin embargo, el migrante no siempre se puede ir con su familia de origen y así deja a sus familiares viviendo en México. Debido al fenómeno de migración, las familias separadas en ambos lados de las fronteras tienden a ser cada vez más y se convierten en familias “transnacionales”. Sin embargo, ¿Qué es una familia transnacional? Las familias transnacionales son aquellas que, de acuerdo a Bryceson y Vuorela (2002), cuentan con miembros que viven una parte o la mayor parte del tiempo separados los unos de los otros y que son capaces de crear vínculos que permiten que sus miembros se sientan parte de una unidad y perciban su bienestar desde una dimensión colectiva, a pesar de la distancia física. De ese modo, las familias se conciben a partir de sus dinámicas de negociación y reconfiguración constante, a través de su capacidad de adaptación en el tiempo y el espacio, y se encuentran conectadas a pesar de las fronteras internacionales por una serie de sentimientos y emocionalidad que se siguen fortaleciendo a lo largo del tiempo.

La migración internacional representa para las familias que se quedan en México, una salida para responder a las necesidades básicas como alimentación, educación y vivienda debido a que garantiza mayores ingresos para ciertos miembros, que posteriormente remiten dinero al desde Estados Unidos a México para apoyar a quienes se quedan. Sin embargo, representa al mismo tiempo una ruptura de la vida y la dinámica familiar, la cual se trata de compensar con una cercanía emocional a través del uso de las tecnologías de comunicación. 
Diversos son los estudios que analizaron la relación entre el uso de tecnologías de comunicación y el apoyo emocional en las familias transnacionales (Baldassar, Baldock \& Wilding, 2007; Kim, 2010; Peñaranda; 2010; Wilding, 2006). Las tecnologías de comunicación se refieren al uso de los medios de comunicación tradicionales como las llamadas telefónicas, el envío de fax y de correo postal, pero también al uso de las nuevas tecnologías virtuales como son el envío de mensajes de texto por celular, llamadas telefónicas, envío de correos electrónicos, uso de redes sociales y videollamadas (Baldassar et. al., 2007; Kim, 2010; Peñaranda; 2010; Wilding, 2006). Asimismo, en estos estudios el apoyo emocional fue definido como las relaciones y la cohesión que establecen los migrantes internacionales, con sus familiares en el país de origen y que pueden mantenerse en las sociedades modernas, a pesar de las distancias geográficas, gracias a los avances en el transporte y las comunicaciones (Baldassar et. al., 2007; Guo, Chi \& Silverstein, 2009).

Retomando las definiciones anteriores, el apoyo emocional son las relaciones familiares y la cohesión o unión entre los migrantes internacionales y sus familiares no migrantes, que no se rompen con la distancia geográfica, sino que se transforman para establecer los vínculos transnacionales y se mantienen gracias a los avances tecnológicos. En una familia transnacional no existe el apoyo emocional sin el uso de tecnologías de comunicación. Las acciones de apoyo emocional consisten en: dar consejo, mostrar solidaridad, empatía y tener muestras de afecto y cariño que los migrantes proporcionaron a sus padres ancianos y a otros familiares en el país de origen, y cuyo medio de transmisión a la distancia fueron las tecnologías de comunicación. Adicionalmente, el apoyo emocional incluyó la preocupación genuina por saber cómo se encontraban los padres al otro lado de la frontera y cómo resolvían sus situaciones de crisis tanto de salud como de la vida cotidiana. Sin embargo, ¿Qué tipo de apoyo emocional se proporciona 
cuando uno de los miembros de la familia transnacional, pertenece a la tercera edad y padece una enfermedad crónica? ¿Qué tecnologías de información utilizan para comunicarse?

\section{Estudios previos sobre familias transnacionales y sus ancianos que padecen enfermedades crónicas}

Para responder a las preguntas que he planteado, es necesario hablar sobre la población de la tercera edad en México. Los ancianos en el país conforman un grupo poblacional grande. Las estadísticas disponibles no miden con precisión el número de familias transnacionales, con familiares de la tercera edad que están vinculadas entre la frontera de México y Estados Unidos, sin embargo, los datos sugieren que tienen representatividad poblacional, ya que en México actualmente hay 8 millones de personas de 60 años, y para el año 2030 se estima que serán 22,200.0 millones (Consejo Nacional de Población, 2005); mientras que los migrantes mexicanos en Estados Unidos tan solo a principios del 2009 superaban los 11,000.0 millones (Centro Hispánico Pew, 2009). En la actualidad vivir más años implica también vivir con más enfermedades crónicas; afrontar la vejez y sus múltiples padecimientos crónicos sigue siendo una responsabilidad de las familias, aunque éstas sean transnacionales.

Las familias transnacionales, con un miembro que padece enfermedades crónicas en la tercera edad han sido estudiadas por Baldassar y cols. (2007) y por Zechner (2008), así como por Zontinni (2007) y Evergeti (2006). Los principales resultados de estas investigaciones refieren que el apoyo emocional forma parte del cuidado transnacional de las personas mayores, $\mathrm{y}$ específicamente consiste en dar ánimos y motivación a los ancianos para que continúen sobreponiéndose a la enfermedad, aconsejarlos en momentos de crisis y manifestarles afecto. Sin 

que ya había sido criticado en el 2008 por Montes de Oca, Molina y Avalos.

Para corroborar lo anteriormente criticado, se hizo una revisión bibliográfica de la situación actual del apoyo emocional en familias transnacionales, con un familiar de la tercera edad, quien además padece enfermedades crónicas. Asimismo, se exploró las tecnologías de comunicación que reportaban estos estudios.

\section{El apoyo emocional de migrantes internacionales a un familiar de la tercera edad que}

\section{padece enfermedades crónicas}

A partir de una revisión bibliográfica, se seleccionaron 47 estudios sobre migración internacional y familias transnacionales que reportaban el tema de apoyo emocional. La revisión incluye artículos, libros, informes de investigación, y tesis las cuales se localizaron a través de varias estrategias. Para los artículos se consultó el índice Pubmed y las siguientes bases de datos en ciencias sociales y salud: Redalyc, Scielo, LILACS, EBSCO, ISI Web of Knowledge, PsycInfo, The Psychology and Behavioral Sciences Collection; The Anthropological Index Online, SocINDEX, OVID, Proquest y Science Direct; para localizar los libros se utilizaron los motores de búsqueda de Google Scholar, y Google Books. Los reportes se buscaron en las siguientes páginas Web: Consejo Nacional de Población; Organización Internacional para las Migraciones; Banco Interamericano del Desarrollo y The Institute for the Integration of Latin America and the Caribbean.

Las palabras clave utilizadas para la localización de las referencias fueron: emotional support; communication technologies; transnational caregiving; elder; ageing parents; ageing; aging; migration y México. 
El cierre de la búsqueda fue el año 2012. Las referencias fueron seleccionadas en base a dos criterios, se seleccionaron aquellas referencias cuyo objetivo o resultado estuviera vinculado con el análisis del apoyo emocional de los migrantes internacionales, en el contexto de las familias trasnacionales. Dicho apoyo era exclusivamente dirigido a los ancianos en situación de dependencia y de enfermedad.

De acuerdo a esta revisión, el apoyo emocional en migrantes internacionales se identificó como: 1) el establecimiento de la comunicación, con otros familiares en México, iniciado por los migrantes, tanto por tecnologías tradicionales como mediante el uso del teléfono, fax, correo postal, y con tecnologías de comunicación virtuales, como el envío de mensajes al celular, uso de redes sociales, correo electrónico y videollamadas (comunicación); 2) el intercambio de vivencias del día a día (intercambio de información); 3) la resolución de problemas o conflictos a pesar de la distancia, este aspecto incluyó la participación del migrante en la toma de decisiones, tanto de salud del anciano como de la familia en general y la acción de aconsejar al anciano cuando así lo requería (solución de conflictos); y finalmente 4) el acompañamiento, participación o presencia del migrante para proporcionar felicitaciones a los familiares en fechas especiales, tales como cumpleaños, día del padre o la madre, Navidad y Fin de Año (fechas especiales). (ver Tabla 1). 
Estudios sobre comunicación y apoyo emocional en familias transnacionales

Autor y año del estudio

Akesson, 2009

Al Sharmani, 2010

Al-Sharmani, 2007

Baldassar y Baldock 2000

Baldassar, 2007b

Baldassar, 2010

Baldassar, et al., 1999

Baldassar, et al., 2007

Canales, 2005

Cohen, 2001

Cong, 2008

Duval, 2004

Evergeti, 2005

González, 2006

Green, 2010

Imserso, 2005

Kabki, 2007

Kalaycioglu 2000

Kanaiaupuni, 2000

Kim, 2010

King y Vullnerati, 2009

Kodwo, 2009

Kodwo y Nguyen, 2008

Luo, 2009

Masson, 2004

Mazzucato, 2007

Merla, $2010^{\mathrm{a}}$

Merla, 2010b

McKay, 2007

Montes de Oca et al., 2008

Mummert, 2010

Oral, 2006

Parreñas, 2001

Peñaranda, 2010

Reynolds y Zontini, 2006

Senyurekli, 2007

Senyurekli y Detzner,2008

Singh, et al., 2010

Solé, 2007

Van der Geest et al., 2004

Voigt-Graf, 2008

\section{Temáticas analizadas}

Fechas

especiales

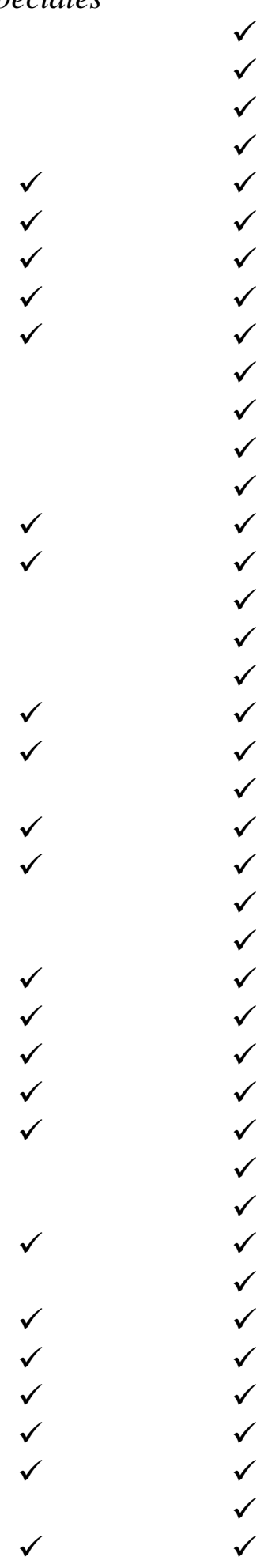

Intercambio de Solución de Participantes información conflictos

$\begin{array}{ll}\checkmark & \checkmark \\ \checkmark & \checkmark \\ \checkmark & \checkmark \\ \checkmark & \checkmark \\ \checkmark & \checkmark \\ \checkmark & \checkmark \\ \checkmark & \checkmark \\ \checkmark & \checkmark\end{array}$

Migrantes

Migrantes

Migrantes

Migrantes

Migrantes

Migrantes

Migrantes

Migrantes

Migrantes

Migrantes

Migrantes

Migrantes

Migrantes

Migrantes

Migrantes

Migrantes

Migrantes

Migrantes

Migrantes

Migrantes

Migrantes

Migrantes

Migrantes

Migrantes

Migrantes

Migrantes

Migrantes

Migrantes

Migrantes

Migrantes

Migrantes

Migrantes

Migrantes

Migrantes

Migrantes

Migrantes

Migrantes

Migrantes

Migrantes

Migrantes 
Autor y año del estudio

Fechas especiales

Wilding, 2006

Zechner, 2007

Zimmer, et al., 2008

Zontini y Reynolds 2007

Zontini, 2004

Zontini, 2010

\section{Comunicación}

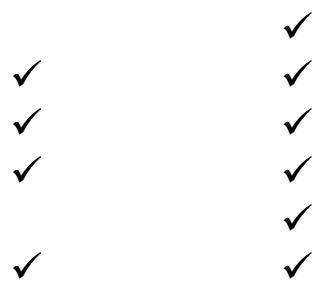

Julio 2014

Fuente: Elaboración propia

\section{El uso de tecnologías de comunicación en migrantes internacionales}

A continuación, presento la manera en que el apoyo emocional se ha vinculado en la literatura, con el uso de tecnologías de comunicación, entendiendo que, debido a la distancia geográfica existente entre los migrantes internacionales y sus familias en el país de origen, el apoyo emocional se lleva a cabo a través del uso de medios de comunicación, como correo electrónico, envío de mensajes de texto por celular y de llamadas telefónicas (Baldassar et al., 2007; Kim, 2010; Peñaranda, 2010; Wilding, 2006).

Correo electrónico. En los 47 estudios se reportó que los migrantes hacían uso del correo electrónico para comunicarse con sus padres ancianos. El correo electrónico fue el medio más utilizado en las familias, según la revisión de la literatura, y que resultaba económico y facilitaba las descripciones detalladas de los eventos a comunicar (Baldassar y Baldock, 2000; Baldassar et al., 2007; Kodwo, 2009; Merla, 2010; Wilding, 2007; Zechner, 2007;).

Sin embargo, de acuerdo a los estudios previos, los ancianos no son quienes utilizan el correo electrónico, sino que el intercambio de mensajes se da entre los familiares en el país de origen y los migrantes, los familiares son quienes sirven de intermediarios entre el migrante y el 
anciano, ya que es común que los ancianos no sepan utilizar las tecnologías informáticas (Wilding, 2006).

Solamente en cinco estudios se reporta el uso de correo postal y el envío de fax como formas de comunicación. Ya que el correo electrónico está sustituyendo al correo postal y al fax. De manera contraria a lo que se reporta en la mayoría de los estudios, Wilding (2006) sostiene que el internet no sustituye a las otras formas tradicionales de comunicación, como cartas o llamadas telefónicas, sino que por el contrario: las complementa.

Mensajes cortos por celular. En 36 de los 47 estudios se reporta la utilización de mensajes por celular o Short Message Service (SMS) como una forma de comunicación. Se reportó que los mensajes de texto por celular al igual que el correo electrónico, se enviaban diariamente, con la finalidad de mantener un contacto permanente entre los migrantes y la familia. De acuerdo a Baldassar y cols. (2007) la diferencia con el correo electrónico es que la información que se comunica es más breve o es para responder a preguntas cortas. Los ancianos tampoco solían utilizar esta tecnología porque, al igual que el internet, tiene un nivel de complejidad mayor en comparación al uso del teléfono para llamadas.

Llamadas telefónicas. En 41 estudios de los 47 sobre apoyo emocional, se reporta el uso de las llamadas telefónicas. Dichas llamadas tenían la finalidad de brindar apoyo emocional al anciano, y el motivo de la llamada se centraba en saludar o al felicitar al anciano en una ocasión especial, por ejemplo su cumpleaños, navidad o día de las madres y también se ha reportado que, en caso de depresión, los hijos migrantes más que cualquier otro pariente de la familia eran quienes solían llamar por teléfono más frecuentemente a sus padres, para brindarles apoyo emocional a través de sus conversaciones (Merla, 2010b). También se reporta en la literatura que los familiares 
no migrantes utilizaban las llamadas telefónicas para informar a los migrantes sobre la condición de salud del anciano y de esa manera tener un vínculo afectivo a pesar de las fronteras ante dificultades cotidianas; en esos momentos los migrantes a pesar de estar lejos se involucraban en las dinámicas familiares, al brindar información, consejos o recomendaciones que ayudaran a resolver las situaciones de crisis de la familia, por ejemplo les aconsejaban alternativas de tratamientos y medicinas; y, haciendo uso de las tecnologías de comunicación, aunque el migrante no estuviera presente podía participar en la toma de decisiones en torno al cuidado de los ancianos y de la vida familiar (Kodwo, 2009).

En la literatura, la mayoría de los estudios que databan de la década de 1980 y 1990 reportaban que las llamadas telefónicas se utilizaban con poca frecuencia debido a sus altos costos. De acuerdo a Kodwo (2009) los migrantes hablaban por teléfono con el anciano u otros familiares dos veces al mes en promedio. En otro estudio se reportó una periodicidad similar pero también se constató que la frecuencia de las llamadas podía aumentar cuando los ancianos presentaban una emergencia de salud o cuando ocurría un desastre natural que amenazaba la integridad de la familia (Merla, 2010a).

Las razones por las que las llamadas telefónicas se utilizaban escasamente, según la revisión de la literatura fueron: sus altos costos, el hecho de que en algunos países donde se encontraba el anciano no contaba con instalaciones telefónicas y otro obstáculo era que debido a la diferencia de horarios entre el país de origen y país de destino del migrante se dificultaba coincidir para conversar en horarios propicios para ambos. En algunos casos, dependiendo de los recursos del migrante, estos obstáculos se podían eliminar, tal es el caso de un estudio en Fiyi, en el cual se reportó que los migrantes pagaban para que se instalaran teléfonos en la ciudad de origen, con el fin de facilitar el contacto con sus familiares (Voigt-Graf, 2008); en otros se reportó que para reducir los costos económicos se hacía uso de las promociones de fin de semana y de las 

la literatura, existían ocasiones en que esta facilidad era relativa, debido a que las condiciones de salud de algunos ancianos les impedía participar en ellas, un ejemplo es el caso de ancianos con artritis, a quienes les resulta complicado hacer una marcación (Wilding, 2006).

\section{Limitaciones encontradas en estos estudios}

En las últimas tres décadas se ha estudiado a las familias transnacionales y se ha tomado como eje de análisis la presencia del apoyo emocional que traspasa las fronteras, lo cual ha aportado un bagaje de sus acciones y experiencias frente a la transnacionalidad y la emocionalidad, sin embargo, encuentro un vacío: los puntos de vista que se han tomado en cuenta para los estudios empíricos, solamente han sido de unos actores sociales y no de todos los involucrados en el proceso, en otras palabras la voz que se ha privilegiado tanto en estudios cuantitativos como cualitativos es la de los informantes migrantes, dejando de lado la perspectiva de los ancianos y otros familiares no migrantes (Akesson, 2009; Baldassar, 1999; Baldassar \& Baldock, 2000; Wilding, 2006). Esto quiere decir que, en dichos estudios sobre las familias transnacionales tampoco se ha considerado a las personas mayores de 60 años, las cuales van en aumento día a día, debido a la inversión de la pirámide poblacional en México. Considerando lo anterior, es pertinente retomar la perspectiva tanto de los migrantes internacionales, como de los familiares no migrantes, especialmente los adultos mayores de 60 años, con alguna enfermedad crónica, para así entender cómo utilizan las tecnologías de comunicación dichas familias y qué relación guardan con la emocionalidad en su vida cotidiana. Incluir a los ancianos, que además tuvieran enfermedades crónicas resultó de dos supuestos: primero, según el INEGI (2012) actualmente el promedio de esperanza de vida en México es de 76 años, aunque es bien sabido que ahora se llega 
a viejo cada vez con más enfermedades crónicas, y por ello con un nivel mayor de dependencia y con mayores necesidades de cuidado. Diversos estudios han demostrado que el cuidado a los ancianos con enfermedades crónicas recae en las familias (Robles, 2003; Robles, 2004; Robles, 2007) y es ahí donde se buscan estrategias para hacer frente a las necesidades de sus ancianos, siendo la migración una de las estrategias principales.

\section{Postulados teóricos de esta investigación}

En base a la revisión teórica, el apoyo emocional del migrante internacional se visualiza en el uso de las tecnologías de comunicación y en el intercambio de información de un país al otro, para aportar un beneficio a la familia; en la resolución de problemas o conflictos y en el acompañamiento, participación o presencia del migrante en fechas especiales y de crisis de algún miembro en el país de origen. El apoyo emocional proporcionado a través de la distancia geográfica está íntimamente vinculado con el uso de tecnologías de comunicación, ya que no podría ser manifestado de otra manera, los migrantes y sus familias han llevado a cabo el apoyo emocional a través de llamadas telefónicas, uso de fax, correo postal, correo electrónico, envío de mensajes de texto por celular, uso de redes sociales y de videollamadas.

En base a los resultados de los estudios empíricos anteriormente citados, mi investigación es novedosa ya que retoma el punto de vista de los migrantes, de los familiares no migrantes y de los ancianos en las familias transnacionales, quienes además de presentar un deterioro y una dependencia propia del envejecimiento, requieren cuidados a sus padecimientos crónicos. Mi investigación además clarifica el papel de las tecnologías de comunicación en el apoyo emocional, lo cual había sido mencionado en estudios anteriores, pero no había sido claramente descrito. Por lo tanto, considerando las deficiencias encontradas en los 47 estudios previos formulé las 
siguientes preguntas de investigación: (1) ¿cómo manifiestan los migrantes internacionales su apoyo emocional hacia sus padres mayores de 60 años con alguna enfermedad crónica, considerando el punto de vista de todas las personas involucradas?; (2) ¿cómo viven la emocionalidad dichas familias transnacionales?, y (3) ¿qué relación tienen las tecnologías de comunicación con el apoyo emocional en las familias transnacionales? 


\section{Método}

\section{Diseño}

Llevé a cabo un estudio de corte cualitativo, descriptivo-interpretativo y retomando elementos del diseño etnográfico, tal como lo plantean Hammersley y Atkinson (1994). La pertinencia del diseño obedece a que me permitiría retomar el saber de los diversos actores involucrados en mi fenómeno de estudio y tener una inmersión en su mundo real, ya que la emocionalidad y el uso de las tecnologías de comunicación de las familias transnacionales se dan en el ámbito cotidiano, y es justo ahí, donde las herramientas etnográficas nos permite acceder, privilegiando el acercamiento al objeto de estudio para describirlo e interpretarlo, como un fenómeno social en su totalidad, es decir desde sus prácticas y también desde sus normas o motivaciones (Atkinson y Hammersley, 1994; Hammersley y Atkinson, 1994; Mitchell, 2007).

\section{Participantes}

El estudio fue hecho en la ciudad de Sahuayo, Michoacán, al occidente de México, con 15 familias transnacionales que además de tener entre sus miembros a migrantes internacionales, contaban con personas mayores de 60 años, quienes padecían una enfermedad crónica y requerían cuidados.

Los participantes fueron 18 ancianos, de los cuales 14 eran mujeres y cuatro hombres. La edad promedio fue 72.8 años y el rango de edad de 62 a 90 años. El estado civil de las ancianas fue: nueve viudas, tres casadas, y dos solteras. Los cuatro hombres estaban casados. Todos eran dependientes y padecían en promedio 2.0 enfermedades crónicas. La enfermedad más frecuente fue la hipertensión; y en segundo lugar fue la diabetes. El resto de enfermedades que padecían fueron: enfermedades cardiovasculares o cardiacas; enfermedades renales; artritis; asma; cáncer; demencia y alcoholismo. Además presentaban dificultades en la deambulación, visión y audición. 
Las ancianas presentaban más enfermedades en comparación con los ancianos varones (ver Tabla

2).

Tabla 2

Características sociodemográficas y de salud de los ancianos entrevistados

\begin{tabular}{|c|c|c|c|c|c|c|}
\hline & \multicolumn{2}{|c|}{$\begin{array}{c}\text { Hombres } \\
n=4\end{array}$} & \multicolumn{2}{|c|}{$\begin{array}{c}\text { Mujeres } \\
n=14\end{array}$} & \multicolumn{2}{|c|}{$\begin{array}{l}\text { Total } \\
n=18\end{array}$} \\
\hline & Núm. & $\%$ & Núm. & $\%$ & Núm & $\%$ \\
\hline Ancianos & 4 & 19.0 & 14 & 71.0 & & 100.0 \\
\hline$E d a d^{*}$ & \multicolumn{2}{|c|}{72.0} & \multicolumn{2}{|c|}{73.7} & \multirow{2}{*}{\multicolumn{2}{|c|}{72.8}} \\
\hline \multicolumn{5}{|l|}{ Estado civil } & & \\
\hline Casado & 4 & 100.0 & 3 & 21.4 & 7 & 38.8 \\
\hline Soltero & 0 & 0.0 & 2 & 14.2 & 2 & 11.1 \\
\hline Viudo & 0 & 0.0 & 9 & 64.4 & 9 & 50.1 \\
\hline \multicolumn{7}{|l|}{ Escolaridad } \\
\hline Analfabeta & 0 & 0.0 & 5 & 35.7 & 5 & 27.7 \\
\hline Primaria & 3 & 75.0 & 8 & 57.2 & 11 & 61.2 \\
\hline Secundaria & 1 & 25.0 & 1 & 7.1 & 2 & 11.1 \\
\hline \multicolumn{7}{|l|}{ Ingresos } \\
\hline Pensión & 2 & 50.0 & 6 & 42.8 & 8 & 44.4 \\
\hline Trabajo Remunerado & 2 & 50.0 & 1 & 7.4 & 3 & 16.6 \\
\hline Renta de propiedades & 0 & 0.0 & 1 & 7.4 & 1 & 5.5 \\
\hline Apoyo familiar & 1 & 25.0 & 14 & 100.0 & 15 & 83.3 \\
\hline Remesas & 1 & 25.0 & 14 & 100.0 & 15 & 83.3 \\
\hline \multicolumn{7}{|l|}{ Arreglos de residencia } \\
\hline Viven solos & 0 & 0.0 & 5 & 35.7 & 5 & 27.7 \\
\hline Solo con pareja & 3 & 75.0 & 3 & 21.4 & 6 & 33.3 \\
\hline Solo con hijos solteros & 0 & 0.0 & 2 & 14.2 & 2 & 11.1 \\
\hline Con pareja e hijos & 1 & 25.0 & 0 & 0.0 & 1 & 5.5 \\
\hline Con hijos casados & 0 & 0.0 & 3 & 21.4 & 3 & 16.6 \\
\hline Con hermanas & 0 & 0.0 & 1 & 7.1 & 1 & 5.5 \\
\hline Enfermedades*: & 2.0 & & 2.5 & & & 2.0 \\
\hline
\end{tabular}

\section{*Promedio}

También participaron 15 migrantes internacionales, con estatus migratorio legal, de los cuales ocho fueron hombres y siete mujeres. Su edad promedio de 43.2 y su rango de edad de 29 a 63 
años. La mayoría eran casados, solamente tres eran solteros. Todos radicaban en Estados Unidos, en primer lugar en el estado de California y en segundo lugar en Illinois, seguido de migrantes en los estados de Arizona y en Carolina del Norte. Todos contaban con empleo formal y se desempeñaban en el área de la construcción, como obreros y como empleados de comercios (ver Tabla 3).

Tabla 3

Características sociodemográficas de los hijos migrantes de los ancianos

\begin{tabular}{|c|c|c|c|c|c|c|}
\hline & & $\begin{array}{l}\text { Iombres } \\
=8\end{array}$ & $\begin{array}{l}M \\
n\end{array}$ & $\begin{array}{l}\text { ujeres } \\
=7\end{array}$ & & $\begin{array}{l}\text { tal } \\
=15\end{array}$ \\
\hline & $N u ́$ & m. $\%$ & $N u ́$ & $\%$ & & n. $\%$ \\
\hline Hijos* & & 3.0 & 3. & & 6 & \\
\hline $\operatorname{Edad}^{*}$ & & 43.0 & 42. & & & 2 \\
\hline Estado civil & & & & & & \\
\hline Soltero & 3 & 37.5 & 0 & 0.0 & 3 & 20.0 \\
\hline Casado & 5 & 62.5 & 7 & 100.0 & 12 & 80.0 \\
\hline Trabajan & & & & & & \\
\hline Sí & & 100.0 & 7 & 100.0 & & 100.0 \\
\hline No & 0 & 0.0 & 0 & 0.0 & & \\
\hline Hijos migrantes*: & & 1.4 & 0. & & & .5 \\
\hline Estatus migratorio & & & & & & \\
\hline Legal & 8 & 100.0 & 7 & 100.0 & & 100.0 \\
\hline Ilegal & 0 & 0.0 & 0 & 0.0 & & 0.0 \\
\hline Lugar de residencio & & & & & & \\
\hline California & 4 & 50.0 & 3 & 43.1 & 7 & 46.8 \\
\hline Illinois & 4 & 50.0 & 2 & 28.5 & 6 & 40.0 \\
\hline Arizona & 0 & 0.0 & 1 & 14.2 & 1 & 6.6 \\
\hline Carolina del Norte & 0 & 0.0 & 1 & 14.2 & 1 & 6.6 \\
\hline
\end{tabular}

*Promedio 


\section{Instrumentos}

Para el objetivo del presente artículo se utilizaron dos cuestionarios y entrevistas semiestructuradas.

Los cuestionarios contenían los datos sociodemográficos de las familias y el nivel de dependencia de los ancianos, así como información sobre los tipos vínculos transnacionales que mantenían los ancianos con sus migrantes, es decir mediante visitas, comunicación o apoyo económico.

Incluí 33 entrevistas a migrantes y ancianos. Todas fueron audiograbadas y posteriormente transcritas en un procesador de texto. A los migrantes los entrevisté por teléfono y cuando se encontraban de visita en Sahuayo. Todas las entrevistas de los ancianos las llevé a cabo en sus domicilios.

Para las entrevistas seguí la técnica de narrativas según Greenhalgh y Hurwitz (1999) utilizando una pregunta central que llevara a las personas a narrar la manera en que mantenían comunicación con sus familiares que vivían lejos, por ejemplo “¿cómo le hace para estar en contacto con su papá/mamá?”. Posteriormente utilizaba otras preguntas como “¿Qué medios de comunicación prefiere y por qué?”; “QQué es lo más complicado al comunicarse?”. Por cada persona llevé a cabo dos entrevistas. En la segunda entrevista traté de indagar sobre los aspectos que no habían quedado claros en la primera entrevista. Las entrevistas para todos los miembros de las familias tenían los mismos contenidos, pero era necesario adaptarlas dependiendo si eran migrantes o no (Ver Tabla 4). 
Guía de entrevista para familias transnacionales

Comunicación a distancia

1. ¿Cómo le hace para estar en contacto con (nombre del familiar migrante o nombre del familiar anciano)?

2. Platíqueme cómo son las llamadas telefónicas con (nombre del familiar migrante o nombre del familiar anciano) (indagar sobre quién las realiza, con qué finalidad se realizan y de qué se habla)

3. Platíqueme cómo usan el fax (indagar frecuencia, quién lo utiliza, y qué finalidad tienen)

4. Platíqueme como usan las cartas (indagar frecuencia, quién las escribe, finalidad, qué temas platican en ellas)

5. Platíqueme cómo usan el internet para estar en contacto con (nombre del familiar migrante o nombre del familiar anciano) (indagar qué formas de comunicación de internet utilizan, saber quién lo realiza, con qué finalidad se realizan y de qué se habla)

6. ¿Qué medios de comunicación prefiere? ¿Por qué?

7. ¿Qué es lo más complicado de comunicarse a distancia?

\section{Emocionalidad}

8. ¿De qué manera le demuestra (nombre de su familiar migrante o nombre del familiar anciano) que está pendiente de usted(es)?

9. ¿De qué manera le ayuda (nombre de su familiar migrante) a usted y a su familia, a pesar de estar lejos?

\section{Visitas del migrante}

10. ¿Cada cuándo los visita (nombre del familiar migrante)? o ¿Cada cuando visita a (nombre del familiar anciano)?

11. Platíqueme cómo son las vistas de (nombre del familiar migrante) (indagar sobre la duración de las visitas, cómo las planean, si cumplen con alguna finalidad en especial, y qué actividades se realizan durante ellas)

Fuente: elaboración propia 
La investigación cumplió con los principios éticos contenidos en la Declaración de Helsinki (1964). La participación de todos los informantes fue voluntaria y con su consentimiento informado, se les explicaron claramente los objetivos y propósitos del estudio. Además se hizo un acuerdo de confidencialidad con cada integrante de la familia que aceptó ser entrevistado, para evitar que durante o posteriormente de la investigación, se gestaran fricciones familiares entre los diversos integrantes, al intervenir en la dinámica propia de las familias.

\section{Procedimiento}

El material proveniente de las 33 entrevistas lo exporté del procesador de texto al software The Ethnograph /Qualis Research (Versión 6.0). Los datos sociodemográficos de las familias y la información sobre los vínculos que mantenían los migrantes con los ancianos, los vacíe en matrices para su análisis posterior.

Posteriormente codifiqué las entrevistas, fui leyéndolas línea por línea para segmentarlas según la información que contenía cada enunciado y les di un código abierto como lo propone Strauss (1987) anotándolo en el margen derecho de un documento impreso. Algunos segmentos contienen información de uno o más códigos debido a que era necesario que ambos tipos de información estuvieran presentes para contextualizar lo que se estaba describiendo. Los códigos resultantes fueron nueve relacionados con el cuidado de los ancianos, por ejemplo: la atención a la enfermedad, el apoyo económico, sistema parental y la comunicación. Para fines de este artículos solo retomo el análisis de lo correspondiente a comunicación y algunos elementos del código sistema parental. El código “comunicación” contenía lo concerniente a: el establecimiento de la comunicación con otros familiares en México, tanto por tecnologías tradicionales como virtuales (comunicación); el intercambio de vivencias del día a día (intercambio de información); 
la resolución de problemas o conflictos a pesar de la distancia, la participación del migrante en la toma de decisiones (solución de conflictos); y el acompañamiento, participación o presencia del migrante para proporcionar felicitaciones a los familiares en fechas especiales. En el código "sistema parental" retomé las experiencias narradas por los migrantes sobre la emocionalidad ante su condición de migrantes y ante la situación de vivir lejos de sus familias. Obtuve un total de 72 cuartillas con información precisa sobre comunicación en las familias transnacionales de mi estudio y sobre la experiencia y emocionalidad de ser migrante, dicho producto fue el material que procedí a analizar para presentar los datos del presente artículo.

\section{Análisis}

El análisis fue de tipo temático y se compuso de dos fases. En la primera fase procedí a imprimir los archivos exportados al software de análisis cualitativo para llevar a cabo un análisis manual. Leí cada documento línea por línea para señalar: 1) qué actividades de comunicación hacían; 2) quiénes estaban involucrados; 3) cuándo la hacían, considerando fecha, y el momento del día o noche en que se lleva cabo la actividad; 4) qué emociones o conflictos habían estado presentes en los migrantes y en los ancianos ante la experiencia de ser familiares transnacionales y ante el cuidado del padecimiento.

En la segunda fase, a partir de los archivos de los códigos identificados, elaboré una matriz para sistematizar la información por familia y entender cómo se comunicaban y qué emociones habían experimentado sus migrantes.

La matriz contenía en la parte superior los datos sobre la familia y contenía columnas para describir los medios de comunicación que utilizaban en las familias, así como las experiencias y emociones de sus migrantes, ante la lejanía geográfica con sus familiares y su país de origen. Finalmente había una columna de observaciones en las matrices. Para finalizar el análisis elaboré 
a las comunicaciones y al aspecto emocional y de esa manera poder hacer una sólida interpretación de mis resultados.

\section{Resultados}

Los resultados se dividen en dos apartados. En el primero describo cómo manifiestan los migrantes internacionales su apoyo emocional hacia sus padres mayores de 60 años, con alguna enfermedad crónica, considerando el punto de vista de todas las personas involucradas. En el segundo apartado presento las tecnologías de comunicación que utilizaban las familias transnacionales, y en el tercero analizo la relación existente entre la emocionalidad y las tecnologías de comunicación, puesto que dichas tecnologías fueron el medio por el cual se transmitió la emocionalidad y se brindó el apoyo emocional.

\section{La emocionalidad en las familias transnacionales}

La emocionalidad de las familias transnacionales se hizo presente en cuatro aspectos: 1) el establecimiento de la comunicación (iniciada por los migrantes) con otros familiares en México, tanto por tecnologías tradicionales como teléfono, fax, correo postal, y con tecnologías de comunicación virtuales, como el envío de mensajes al celular, uso de redes sociales, correo electrónico y videollamadas (comunicación); por ejemplo:

“En mi familia la comunicación más recurrente es con llamadas telefónicas, intentando que sean por lo menos dos por semana, usamos más el teléfono, contratamos un plan de llamadas ilimitadas para aprovechar al máximo el tiempo en la línea. Adicional a mis llamadas hacemos una conferencia semanal con mi hermana que se encuentra en California, pero no hay un acuerdo específico con ella (hermana). Más bien cuando hay algún tema que afecta a mis papas hacemos conferencias para tocar los temas. 
2) en las prácticas de intercambio de vivencias del día a día, lo cual consistía en compartir

a detalle las actividades cotidianas que se hacían a un lado y a otro de la frontera. Por ejemplo:

"Le llamo a mi mamá varias veces al día, acostumbro siempre en la mañana para preguntarle cómo amaneció y qué desayunó, luego le vuelvo a hablar otra vez por la tarde, ya cuando recogí a los niños de la escuela y entonces le platico las cosas que he hecho en el día, le preguntó qué está haciendo, le pido recetas, le platico de mis hijos; luego ya le llamo en la noche, cuando ella ya se va a dormir, digamos que todo el día estoy pendiente desde aquí”.

Hubo incluso migrantes que aprovechaban los tiempos de traslado del trabajo a casa o viceversa, para llamar a México utilizando sus teléfonos celulares y así poder platicar diariamente las vivencias laborales y cotidianas con sus padres ancianos.

3) en la resolución de problemas o conflictos a pesar de la distancia, este aspecto incluyó la participación del migrante en la toma de decisiones, tanto de salud del anciano como de la familia en general y la acción de aconsejar al anciano cuando así lo requería, por ejemplo:

“Mi mamá es una persona para algunas cosas muy fuerte, superó su enfermedad cuando le diagnosticaron cáncer, pero también necesita a veces que le demos aliento, ahora que enfermó de la fibromialgia, yo traté de investigar qué era esa enfermedad y de entenderla, entonces ya le llamaba y le decía 'ánimo mamá, todo va a estar bien, échale ganas, ve ahora con este otro médico que te dijo tía y pídele opinión. Siempre estoy preguntándole qué le dijeron los médicos y también yo comparo opiniones para ayudarla a elegir lo mejor, también me informo para saber de qué se trata”.

y, 4) en el proceso de acompañamiento, participación o presencia del migrante para proporcionar felicitaciones a los familiares en fechas especiales, tales como cumpleaños, día del padre o la madre, Navidad y Fin de Año, por ejemplo:

"Mi hijo [migrante] nunca olvida mi cumpleaños, ni el diez de mayo, me llama para felicitarme, el año pasado le llamó primero a su hermana [no migrante] y le pidió que me comprara un arreglo de flores, con su nombre, fue un buen detalle, luego él me habló y me felicitó y me preguntó si me gustaron las flores. Este año vino para el diez de mayo y me llevó a comer a un restaurante muy hermoso, ahí me regalo también un rosario de oro". 
Cabe mencionar que, los migrantes que más se comunicaban por teléfono fueron los mismo que planeaban al menos una visita al año para convivir con los ancianos, puesto que era más viable que se tenía más tema de conversación para platicar, dado que el nivel de comunicación se había nutrido a través de las tecnologías de comunicación y se reproducía en cada visita, también coincidió que dichos migrantes al estar más involucrados emocionalmente eran quienes buscaban otras estrategias adicionales para estrechar el vínculo familiar entre el anciano y el migrante, por ejemplo el regalo de artículos y de dinero. Lo anterior significa que el constante uso de tecnologías de comunicación era el preámbulo para que los migrantes del estudio se involucraran emocionalmente con sus familias y fortalecieran sus vínculos mediante visitas y apoyo económico, en las quince familias del estudio se reportó el obsequio de dinero como una forma de apoyo emocional. Los migrantes enviaban dinero como un regalo a sus padres en fechas especiales, por ejemplo cumpleaños, navidad y día de las madres. En otras palabras, los migrantes que más se comunicaban eran los que generalmente planeaban visitas a los hogares en el país de origen durante las vacaciones, dichas visitas se llevan a cabo en temporadas de verano y de invierno, donde los migrantes además de ir a su país de origen a descansar, cumplían con el propósito de convivir con el anciano y mediante acompañamiento físico y conversaciones le proporcionaban apoyo emocional, de esa manera expresaban su emocionalidad, fortalecían los lazos familiares y los vínculos transnacionales con el anciano y con otros miembros de la familia y luego regresaban a Estados Unidos con la disposición de seguir fortaleciendo dichos lazos, lo cual formaba un ciclo de constante apoyo emocional, independientemente de que el migrante internacional se encontrara en México o en Estados Unidos. Las visitas en fechas especiales fueron durante los cumpleaños del anciano, o en eventos familiares como matrimonios, graduaciones o bautizos, lo cual contribuía a fortalecer los vínculos y la emocionalidad de las familias transnacionales, ya que representaban 
una forma de convivencia con el anciano y una manera de hacerlo sentir acompañado en un acontecimiento importante.

El principal obstáculo tanto en la comunicación como en la manifestación de la emocionalidad para los integrantes de las familias de mi estudio, fue que los ancianos, en su mayoría, desconocían el manejo de las nuevas tecnologías, a pesar de que a varios de los ancianos se les trató de enseñar cómo usar tabletas y computadoras, por ello considero que integrar a los ancianos en el uso de la tecnologías de comunicación vanguardistas es un reto que toca cumplir a las familias transnacionales, en conjunto, ya que es en conjunto que viven luchando por sentir esa tan anhelada "cercanía" que proporciona lo virtual.

En resumen, mis resultados reportan que, considerando el punto de vista de todas las personas involucradas, los migrantes internacionales manifiestan su apoyo emocional hacia sus padres mayores de 60 años con alguna enfermedad crónica, de la siguiente manera: 1) con el establecimiento de la comunicación, tanto por tecnologías tradicionales como teléfono, fax, correo postal, y con tecnologías de comunicación virtuales, como el envío de mensajes al celular, uso de redes sociales, correo electrónico y videollamadas; 2) en las prácticas de intercambio de vivencias del día a día, lo cual consistía en compartir a detalle las actividades cotidianas que se hacían a un lado y a otro de la frontera; 3) en la resolución de problemas o conflictos a pesar de la distancia, este aspecto incluyó la participación del migrante en la toma de decisiones, tanto de salud del anciano como de la familia en general y la acción de aconsejar al anciano cuando así lo requería, y 4) en el proceso de acompañamiento, participación o presencia del migrante para proporcionar felicitaciones a los familiares en fechas especiales, tales como cumpleaños, día del padre o la madre, Navidad y Fin de Año. Lo anterior responde a la pregunta de investigación que señala la forma de cómo manifiestan los migrantes internacionales su apoyo emocional hacia sus padres 
mayores de 60 años con alguna enfermedad crónica, considerando el punto de vista de todas las personas involucradas.

Además, este estudio refleja que las familias transnacionales viven la emocionalidad mediante el establecimiento de la comunicación con diferentes tecnologías; el intercambio de vivencias del día a día; la resolución de problemas o conflictos a pesar de la distancia, y con el acompañamiento, participación o presencia del migrante para proporcionar felicitaciones a los familiares en fechas especiales. Así, lo anterior responde a la pregunta de investigación que señala la forma de cómo viven la emocionalidad dichas familias transnacionales y se confirman las categorías establecidas en la revisión teórica, lo cual aporta al estudio validez teórica.

\section{Tecnologías de comunicación utilizadas en las familias del estudio}

El uso de diversas tecnologías de comunicación fue el medio por el cual los migrantes mantenían vínculos afectivos con sus padres mayores de 60 años, quienes además padecían enfermedades crónicas. El uso de tecnologías de comunicación también fungió como un medio para manifestar la emocionalidad y el apoyo emocional de los migrantes hacia sus padres. En las quince familias tenían acceso al uso del teléfono en casa. En ocho familias los migrantes utilizaban paquetes de llamadas ilimitadas a México y en diez familias llamaban con tarjetas telefónicas prepagadas. En dos familias enviaban mensajes de celular; en tres hablaban por celular y en cuatro utilizaban el internet mediante correo electrónico, redes sociales y videollamadas.

En seis familias solamente utilizaban tarjetas telefónicas de pre-pago para comunicarse; en cuatro solamente paquetes de llamadas ilimitadas; y cinco familias utilizaban más de una tecnología de la siguiente manera: 1) Tarjetas de pre-pago y uso de celulares; 2) Paquetes de llamadas ilimitadas, mensajes de texto e internet; 3) Tarjetas de pre-pago, paquetes de llamadas ilimitadas e internet; 4) Tarjetas de pre-pago, uso de celulares, paquetes de llamadas ilimitadas, 
mensajes de texto e internet; 5) Tarjetas de pre-pago, uso de celulares, paquetes de llamadas ilimitadas e internet (Ver Tabla 5).

\section{Tabla 5}

Uso de tecnologías de comunicación

\begin{tabular}{|c|c|c|c|c|c|}
\hline Familia & Telefonía Ilimitada & Tarjetas de prepago & Mensajes de texto & Celular & Internet \\
\hline Familia 1 & & $*$ & & & \\
\hline Familia 2 & & $*$ & & $*$ & \\
\hline Familia 3 & $*$ & & & & \\
\hline Familia 4 & $*$ & & & & \\
\hline Familia 5 & & $*$ & & & \\
\hline Familia 6 & $*$ & & $*$ & & $*$ \\
\hline Familia 7 & $*$ & $*$ & & & $*$ \\
\hline Familia 8 & $*$ & & & & \\
\hline Familia 9 & & $*$ & & & \\
\hline Familia 10 & $*$ & $*$ & $*$ & $*$ & $*$ \\
\hline Familia 11 & $*$ & $*$ & & $*$ & $*$ \\
\hline Familia 12 & & $*$ & & & \\
\hline Familia 13 & & $*$ & & & \\
\hline Familia 14 & & $*$ & & & \\
\hline Familia 15 & $*$ & & & & \\
\hline
\end{tabular}

Fuente: elaboración propia

Llamadas telefónicas. Pese a que la era virtual se hace presente en nuestros días, el uso del teléfono sigue siendo la principal forma de comunicación en las familias transnacionales. Los participantes migrantes del estudio reportaron que hacían de tres a doce llamadas semanales a sus padres en México. Fueron las migrante mujeres quienes hacían más llamadas, llegando a realizar en algunos hogares hasta cinco llamadas al día. El objetivo de las llamadas era saber cómo se encontraba la salud de sus padres, platicarles lo que habían hecho en el día, preguntar qué les había dicho el médico, darles ánimos o consejo y también consultarles a sus padres y a otros familiares si necesitaban algún artículo o insumo en especial para hacérselos llegar desde Estados Unidos, ya fuera en especie o en dinero. 
Frente al uso del teléfono y otras tecnologías, se ha desdibujado por completo el uso de las

cartas por correo postal, los costos del teléfono han disminuido con el paso de los años y existe además una percepción de que el envío de cartas hace más lenta la comunicación y por lo tanto está cayendo en desuso:

"Yo siempre me comuniqué por teléfono porque para me era más fácil, mandar carta se me hacía una pérdida de tiempo [Estados Unidos] gracias a Dios ya no son los tiempos de antes en que solamente por carta y por teléfono no podías hacerlo por cuestiones económicas, era muy costoso, entonces ahorita todo se ha puesto más al alcance de la mano y si el teléfono está más accesible [económicamente] y siempre fue por teléfono y siempre pensar también en dar apoyo más que nada en la oración”.

El papel de los migrantes fue decisivo en el intercambio de información para la búsqueda de tratamientos de salud de sus padres, ya que los migrantes no solo daban aliento a los ancianos y a los demás familiares, también daban consejos y apoyo espiritual a los ancianos frente a problemas que les aquejaban y además algunos de ellos fungían como portadores de información: "Yo si les daba recomendaciones, a mis hermanas siempre les preguntaba cuando hablaba con ellas ¿cuáles son sus síntomas?, ¿que está presentando? ¿Qué color es el excremento? ¿Cómo está actuando?, ¿cómo están sus ojos?, ¿cómo está su vista?, les explicaba cómo se puede bañar a una persona sin lastimarla (Rayo, enfermera, migrante internacional)”.

Hacer llamadas telefónicas al país de origen, representaba para los migrantes una forma de cercanía con sus padres y sus demás familiares. Los migrantes manifestaron sentimientos inexplicables "de querer estar en ahí y no poder hacerlo y entonces compensarlo con las llamadas telefónicas constantes o el envío de dinero", tal como lo narra Octavio:

"Me siento afortunado ahora de tener papeles, cuando no los tenía y no podía ir era una impotencia muy fuerte. Cuando tus padres se enferman y no puedes ir porque tienes que trabajar y cumplir aquí, te viene un sentimiento que no sabría cómo explicar y lo que haces tú es llamar para que sientas y sentir que estás ahí, o mandar dinero, para lo que se necesite, yo soy una persona que puede entrar y salir de Estados Unidos, en cambio hay otras personas que no pueden, sí pueden salir, pero no pueden regresar, entonces tienen que tomar la decisión de su vida o van a verlos o mandar dinero, así es, es muy duro, duele, 
por eso me considero afortunado ahora [que tengo papeles] a diferencia de otras personas".

En algunas ocasiones que el migrante llamaba al país de origen, en lugar de hablar con el anciano, prefería hablar con otro familiar o alguna persona externa a la familia, para pedir que le dieran puntos de vista sobre el estado de ánimo del anciano y sobre su salud, también aprovechaba para solicitar que estuvieran "pendientes" de él y le dieran ánimos o pedían que le avisara al anciano y a la familia que habló con terceros porque no se pudo comunicar a la casa del anciano.

Mensajes de texto por celular. Los mensajes de texto fueron utilizados como una manera complementaria de las llamadas telefónicas, los familiares en el país de origen avisaban al migrante que llamara mediante mensajes, siendo esto más barato que marcarle a su teléfono. Los migrantes también utilizaron mensajes de texto para expresar su afecto a sus padres cuando les era difícil manifestárselo mediante una llamada telefónica o una videollamada. El mensaje de texto fue útil para enviar información corta y precisa o para acordar el momento en que el anciano o familiares estarían en casa, para que el migrante pudiera hablarles por teléfono o por videollamada. Finalmente sirvieron como recordatorios de interés genuino de parte del migrante al anciano tales como: "Cuídate mucho, no olvides tomar tu medicina". En la mayoría de las familias, eran otros familiares, distintos a los ancianos, quienes leían a los ancianos, los mensajes de texto de los migrantes, también hubo ancianos, principalmente los varones, quienes hacían uso de manera fluida de los celulares para recibir y contestar mensajes de texto.

Internet. El uso de internet se presentó por tres medios: envío de correos electrónicos; uso de redes sociales como Facebook para intercambio de mensajes y fotografías; y el uso de videollamadas. 
El correo electrónico se empleó en las familias para dar noticias, resolver conflictos familiares, brindar apoyo emocional al anciano cotidianamente o durante tiempos de crisis, proporcionar consejos a los familiares en relación a las opciones de tratamiento y la compra de medicina, y para propiciar el intercambio de opiniones que sirvieran para aprovechar mejor los recursos familiares.

El mensaje por correo electrónico en la mayoría de las familias se intercambiaba en promedio dos veces a la semana, y se combinaba con las llamadas telefónicas y con los mensajes de texto, era común que los migrantes llamaran por teléfono avisando que habían manado información vía correo electrónico para proporcionar cierta información importante.

En general, fueron las generaciones más jóvenes, las que motivaron a los ancianos que tuvieran contacto con los migrantes de estas maneras. Por estos medios los migrantes solían enviar fotografías del día a día para que sus padres ancianos pudieran verlos; también llegaron a crear videos acompañados de fotografías animadas para demostrar su cariño hacía sus padres ancianos. Para los ancianos fue asombrosa la primera vez que vieron a sus hijos a través de una pantalla, sin embargo ha sido una práctica que cada vez se ha acentuado más en las familias. Los participantes reportaron que al menos una vez a la semana o una vez al mes organizan videollamadas para saludar a sus padres y a otros familiares que estén presentes, esos les implica una sensación de cercanía y bienestar a pesar de la distancia.

Otra estrategia que siguieron los migrantes, en el uso del internet, fue contactar a vecinos cercanos a sus padres, para preguntarles cómo los veían y enviarles saludos haciendo uso del Facebook, también los familiares en el país de origen, cuando no tenían internet, llegaron a solicitar a los vecinos que les avisaran a los migrantes por el Facebook que necesitaban hablar con ellos.

En síntesis, la tecnología de comunicación que más se utilizó en las familias fue el teléfono, en primer lugar con la modalidad de llamadas ilimitadas y en segundo lugar con las tarjetas pre- 
pagadas y la que menos se utilizó fueron los mensajes de texto por el celular. El uso del internet tuvo una presencia importante en las familias, sin embargo son otros familiares, y no el anciano quienes llevan a cabo la dinámica de las videollamadas o el intercambio de correos electrónicos. Hay un apoyo constante de otros miembros de la familia para que los ancianos puedan hacer uso de las tecnologías de comunicación con los migrantes.

\section{Relación entre tecnologías de comunicación y emocionalidad en familias transnacionales}

El papel que juegan las tecnologías de comunicación en las familias transnacionales es precisamente el establecimiento de vínculos emocionales y afectivos a través de la distancia, es decir que las tecnologías de la comunicación representan el medio y el vehículo mediante el cual, las familias se relacionan sin importar su ubicación geográfica, las tecnologías de comunicación han sido pues las promotoras de la "proximidad" en el vivir cotidiano en ambos lados de las fronteras internacionales. Lo anterior responde a la pregunta de investigación que señala la relación que tienen las tecnologías de comunicación con el apoyo emocional en las familias transnacionales.

Cada familia de mi estudio pudo romper las distancias geográficas mediante prácticas en su comunicación y en su emocionalidad que los hace estar presente "aquí" y "allá", es decir hacerse presentes sin estar físicamente en el mismo lugar que los padres ancianos o los hijos migrantes.

Sin importar la posibilidad de contratar o utilizar los servicios de internet o las llamadas ilimitadas, todas las familias coincidieron en que sus formas de comunicación se emplearon para vivir la emocionalidad, los vínculos afectivos y proporcionar apoyo emocional en ambos lados de la frontera.

Finalmente, las nuevas generaciones como una prueba misma de apoyo a las personas mayores de la familia, participaron al ayudarles a utilizar las nuevas tecnologías, tales como 

contexto social donde los alcances tecnológicos en comunicación estaban a su disposición, pertenecían a una zona urbana, dotada de todos los servicios de comunicación actuales, y aunque la dinámica familiar en cuestión de comunicaciones y emocionalidad giró en torno a los adultos mayores, con enfermedades crónicas; fue un logro colectivo, tanto de las generaciones más jóvenes, como de las más envejecidas para innovar en su vivir transnacional y enseñarse mutuamente a manejar las diversas tecnologías, para apoyarse emocionalmente y permanecer “juntas” a pesar de la distancia.

\section{Discusión}

A lo largo de las últimas dos décadas, en el estudio sobre familias transnacionales y su emocionalidad, el hallazgo central ha girado en torno a que, el uso de tecnologías de la comunicación funge como un vehículo para expresar y brindar apoyo emocional a través de la distancia geográfica. Actualmente el acceso a las tecnologías de comunicación es cada vez más generalizado y con un costo más bajo, por lo tanto la distancia entre los migrantes internacionales y sus familias en su país de origen se puede acortar cada vez más, algunos autores lo describen como intimidad virtual, otros como un (con)vivir transnacionalmente, pero lo que es común es la conclusión del papel central que los medios de comunicación y las tecnologías juegan en el fortalecimiento de vínculos y lazos transnacionales a pesar de las fronteras internacionales.

Considerando lo anterior y después de haber implementado una investigación que intentó superar las limitaciones de estudios previos, las tres preguntas de investigación fueron respondidas y dichos resultados coinciden con lo mencionado por Baldassar y cols. (2007), Peñaranda (2009) y Wilding (2006) en los estudios analizados en la revisión de la literatura. Encuentro coincidencias en que las familias diversificaron su manera de comunicación a través de distintas tecnologías, 
como el uso de correo electrónico, llamadas telefónicas y mensajes de texto al celular, sin embargo adicionalmente identifiqué que mis familias también incorporaban el uso de videollamadas y redes sociales, además de que eran los miembros de la familia más jóvenes, quienes enseñaban a los ancianos a usar las nuevas tecnologías.

Este estudio demuestra que para que los migrantes internacionales puedan manifestar su emocionalidad y el apoyo emocional hacia sus padres necesitan hacer uso de diversas tecnologías de comunicación, dichas evidencias provienen de retomar el punto de vista de todas las personas involucradas al interior de las familias transnacionales. Por otro lado demuestro que las tecnologías de comunicación, la emocionalidad y el apoyo emocional en las familias transnacionales guardan una estrecha relación entre sí, puesto que las primeras son el primer medio por el que la emocionalidad y el apoyo emocional pueden establecerse y manifestarse hacia el país de origen, lo cual no había sido reportado en ningún otro estudio. Lo anterior supera a ciertos estudios que sólo enlistaron las actividades de comunicación en las familias transnacionales, pero no las describieron dichas prácticas con detalle (Akesson, 2009; Baldassar y cols. 2007; Kim, 2010, Zechner, 2007).

Además, mi trabajo subsana las deficiencias que encontré en investigaciones pasadas (AlSharmani-2007; Al-Sharmani-2010; Baldassar y cols. 2007; Kim, 2010; Kodwo, 2009; Merla, 2010; Peñaranda, 2010; Wilding, 2006;) debido a que basé mi estudio en considerar el punto de vista de todas las personas involucradas, lo cual no hicieron los estudios pasados, de esa manera considero que he dado un paso adelante, en la investigación sobre familias transnacionales, en el sentido de que, al integrar las diversas perspectivas potencialicé el acercamiento al objeto de estudio, teniendo una visión en conjunto del fenómeno, de esa manera es que pude identificar que las familias hacían uso también de tecnologías virtuales, a pesar de que las personas mayores de 60 años no supieran usarlas, porque sus familiares hacían alusión de que les apoyaban en ese 
retoman la importancia del (con)vivir transnacional, afirmo aspectos similares en el sentido de que las familias transnacionales hacen uso de diversas tecnologías para (con)vivir de manera transnacional y además señalo que la práctica específica para hacerlo es el acompañamiento del día a día que consiste en que, a pesar de la distancia geográfica, las familias se comunican constantemente y comparten sus vivencias, incluso de una manera más estrecha que con otros familiares que viven en el mismo país.

\section{Conclusiones}

Los resultados de mi estudio coinciden con la literatura sobre familias transnacionales que analizan el uso de medios de comunicación, como una forma de fortalecimiento a la emocionalidad de las familias y como un medio para los migrantes de proporcionar apoyo emocional y participar en la vida cotidiana de la familia, a pesar de la distancia geográfica (Kim, 2010; Kodwo, 2009; Merla, 2010; Peñaranda, 2010; Wilding, 2006). Pero agregan el punto de vista de otros actores involucrados como personas mayores de 60 años y familiares no migrantes, lo cual potencializa mi acercamiento al tema de investigación y presenta nuevos panoramas, por ejemplo el papel que juegan las nuevas generaciones para ayudar a los ancianos a utilizar las nuevas tecnologías.

En mi estudio constaté que el apoyo emocional, además de brindarse por medios de comunicación, se representó en el obsequio de dinero o regalos en fechas especiales para ancianos y en las visitas, lo cual me lleva a reflexionar que el apoyo emocional es determinado por los recursos económicos y tecnológicos con los que se cuentan en el país de origen y en el país de residencia del migrante.

Concluyo que todas las tecnologías de comunicación tienen sus ventajas y desventajas para cada familia, sin embargo existen un factor común que facilita el uso del internet y de las llamadas 
telefónicas frente a otras tecnologías de comunicación: el aumento en el acceso a Internet a lo largo del mundo, cada vez es más fácil y más económico tener este servicio en los hogares, y la infinidad de compañías telefónicas y de planes en el mercado para utilizar la larga distancia telefónica a bajos costos. Por otro lado, solamente hay una ventaja de los correos electrónicos y el uso de redes sociales sobre las llamadas telefónicas, lo cual es el fácil acceso y posibilidad de almacenar la información intercambiada entre migrantes y familiares en el país de origen. Los migrantes internacionales cada vez más pueden recurrir al uso de tecnologías de comunicación para afrontar sus sentimientos de nostalgia y soledad y para aliviar esa necesidad de co-presencia inmersa en la transnacionalidad de sus vidas.

Como sugerencia, propongo que en posteriores estudios también se integren todas las perspectivas o al menos más de una, para entender el fenómeno de manera integral desde múltiples perspectivas. También logré visibilizar que un migrante al expresar y vivir su emocionalidad utilizando constantemente tecnologías de comunicación con su familia en el país de origen, es un migrante que puede integrarse más fácilmente a las dinámicas de la familia, no sólo en la resolución de conflictos y en el intercambio de información, sino también en la convivencia durante visitas y eventos especiales y en lo que respecta al apoyo económico. Lo anterior no había sido analizado en otros estudios.

Frente a este panorama, se abre también la posibilidad de crear líneas de investigación enfocadas a los migrantes nacionales, para saber si ocurren fenómenos similares o son distintos en relación a los migrantes internacionales. Por otro lado, sugiero incluir poblaciones rurales en los estudios posteriores, ya que de acuerdo a la revisión de la literatura y a mi estudio mismo, se analizan las poblaciones urbanas solamente. Sería pertinente entender qué diferencias o similitudes se encuentran también en las poblaciones rurales y poder así introducir nuevos elementos al tema. Finalmente sugiero considerar la posibilidad de hacer estudios comparativos a partir de los datos 

rasgo relevante es que contempló solamente migrantes internacionales con estatus migratorio legal, en la agenda podría estudiarse qué ocurre con los migrantes con estatus migratorio ilegal.

\section{Referencias bibliográficas}

Akesson, L. (2009). Remittances and inequality in Cape Verde: the impact of changing family organization. Global Networks, 9(3), 381-398.

Al-Sharmani, M. (2007). Transnational Somali families in Cairo. Refuge, 24(1), 88-98.

Al-Sharmani, M. (2010). Transnational family networks in the Somali diaspora in Egypt: women's roles and differentiated experiences. Gender, Place and Culture, 17(4), 499-518.

Atkinson, P., \& Hammersley, M. (1994). Ethnography and participant observation. In N. Denzin \& Y. LIncoln (Eds.), Handbook of qualitative research (pp. 248-261). London: Sage Publications.

Ávila, J. L., Castro, J., Fuentes, C., \& Tuiran, R. (2000). Remesas: Montos y distribución regional en México. In R. Tuiran (Ed.), Migración México-Estados Unidos, Presente y Futuro. México D.F.: Consejo Nacional de Población.

Ávila, M. (2000). Características de los hogares receptores de remesas en la región tradicional de emigración. El Colegio de la Frontera Norte, Tijuana.

Baldassar, L. (2007a). Transnational families and aged care: The mobility of care and the migrancy of ageing. Journal of Ethnic and Migration Studies, 33(2), 275-297.

Baldassar, L. (2007b). Transnational families and the provision of moral and emotional support: the relationship between truth and distance. Identities: Global Studies in Culture and Power, 14(385-409). 
Baldassar, L. (2008). Missing kin and longing to be together: emotions and the construction of copresence in transnational relationships. Journal of Transcultural Studies, 29(3), 247-266.

Baldassar, L. (2010). Obligation to people and place: The national in culture of caregiving. In L. Baldassar (Ed.), Intimacy and Italian migration: Gender and domestic lives in a mobile world (pp. 171-187). Rose Hill: Fordham University Press.

Baldassar, L., \& Baldock, C. (2000). Linking migration and family studies: Transnational migrants and the care of ageing parents.In B. Agozino (Ed.), Theoretical and methodological issues in migration research. Interdisciplinary and international perspectives (pp. 61-88). Aldershot: Ashgate.

Baldassar, L., Baldock, C. V., \& Lange, C. (1999). Immigration and transnational care-giving: public policies and their impact on migrants' ability to care from a distance. In M. Collis, L. Munro \& S. Russell (Eds.), Challenges for a new millennium. Melbourne: TASA.

Baldassar, L., Vellekoop, C., \& Wilding, R. (2007). Families caring across borders. Migration, ageing and transnational caregiving. New York: Palgrave Macmillan.

Baldock, C. V. (2000). Migrants and their parents. Caregiving from a distance. Journal of Family Issues, 21(2), 205-224.

Bryceson, D. \& Vuorela, U. (2002). The transnational family. New European frontiers and global networks. Oxford: Berg.

Canales, A. I. (2005). El papel de las remesas en la configuración de relaciones familiares transnacionales. Papeles de Población (044), 149-171.

Castillo, R. A., \& Larios, A. (2008). Remesas y desarrollo humano: el caso de Zacatecas. Región y sociedad, 20(41), 117-144.

Centro Hispánico Pew (2009) Estudio binacional "Inmigrantes mexicanos: ¿cuántos vienen? ¿Cuántos se van?’. 
Cohen, J. H. (2001). Transnational migration in rural Oaxaca, Mexico: dependency, development, and the Household. American Anthropologist, 103(4), 954-967.

Cohen, J. H., Rodríguez, L., \& Fox, M. (2008). Gender and migration in the central valleys of Oaxaca. International Migration, 46(1), 79-101.

Consejo Nacional de Población (2004). Estudio binacional México-Estados Unidos de América sobre migración, de 1995-2005.

Consejo Nacional de Población (2005). U. S. Census Bureau, 15-percent sample 1970, 5-percent sample 1980, 5-percent sample 1990, 5-percent sample 2000 y American Community Survey.

Cong, Z. (2008). Children's migration and the financial, social, and psychological well-being of older adults in rural China. The University of Southern California, Los Ángeles.

Conway, D. \& Cohen, J. (1998). Consequences of migration and remittances for Mexican transnational communities. Economic Geography, 74(1), 26-44.

Duval, D. T. (2004). Linking return visits and return migration among commonwealth Eastern Caribbean migrants in Toronto. Global Networks, 4(1), 51-67.

Escrivá, A. (2004). Securing care and welfare of dependants transnationally: Peruvians and Spaniards in Spain. Working Paper Number WP404. Oxford: Oxford Institute of Ageing.

Evergeti, V. (2006). Living and caring between two cultures. Narratives of Greek women in Britain. Community, Work and Family, 9(3), 347-366.

Faist, T. (2002). The volume and dynamics of international migration and transnational social spaces. Oxford: Oxford University Press.

Faist, T., Pitkänen, P., Gerdes, J., \& Reisenauer, E. (2010). Transnationalisation and institutional transformations. Bielefeld: University of Bielefeld/TRANS-NET Project. 
Gherghel, A. (2010). Transnational practices of care: The Azorean Migration in Quebec (Canada).

In J. Chapple (Ed.), Boundaries: Dichotomies of keeping in and keeping out (pp. 125-142). Oxford: Inter-Disciplinary Press.

Göransson, K. (2009). The binding tie: Chinese intergenerational relations in modern Singapore. Honolulu: University of Hawaii Press.

Greehalgh, T. \& Hurwitz, B. (1999) Narrative Based Medicine: why study narrative? British Medical Journal; 318; 48-50.

Guo, M., Chi, I., \& Silverstein, M. (2009). Intergenerational support of Chinese elders with migrant children: Do sons’ or daughters' migrations make a difference? Intergenerational support of Chinese rural elders. Journal of Gerontological Social Work, 52(5), 534-554.

Hammersley, M., \& Atkinson, P. (1994). Etnografía. Métodos de investigación (M. Aramburu, Trans. Vol. 69). Barcelona: Paidós.

Declaración de Helsinki de la Asociación Médica Mundial (1964). Principios éticos para las investigaciones médicas en seres humanos. http://www.wma.net/s/policy/17-c_s.html

Kabki, M. (2007).Transnationalism, local development and social security: the functioning of support networks in rural Ghana. Leiden: African Studies Centre.

Kalaycioglu, S., \& Rittersbergertilic, H. (2000). Intergenerational solidarity networks of instrumental and cultural transfers within migrant families in Turkey. Ageing and Society, $20,523-542$.

Kanaiaupuni, S. (2000).Leaving parents behind: migration and elderly living arrangements in Mexico. CDE Working Paper No. 99-16. Madison: Center for Demography and Ecology. University of Wisconsin-Madison.

Kim, H. N. (2010). Maintaining intergenerational solidarity in Mexican transnational families. University of Minnesota, Minneapolis. 
King, R., \& Vullnetari, J. (2009). The intersections of gender and generation in albanian migration, remittances and transnational care. Geografiska Annaler: Series B, Human Geography, 91(1), 19-38.

Knodel, J., Yawattana, J. K., Saengtienchai, C., \& Wiwatwanich, S. (2010). How left behind are rural parents of migrant children? Evidence from Thailand. Ageing \& Society, 30, 811-841.

Kodwo, S. R. (2009). Determinants of international long-distance eldercare: Evidence from ghanaian immigrants in the United States. Virginia Commonwealth University, Richmond.

Kodwo-Nyameazea, Y., \& Nguyen, P. V. (2008). Immigrants and long-distance elder care: An exploratory study. Ageing International, 32(4), 279-297.

Koerin, B. B., \& Harrigan, M. P. (2002). P.S. I love you: Long-distance caregiving. Journal of Gerontological Social Work, 40(1/2), 63-81.

Loza, M. (2007). Jefaturas de hogar: El desafío femenino ante la migración transnacional masculina en el sur del Estado de México. Migraciones Internacionales, 4(2), 33-60.

Luo, B. (2009). The impact of rural-urban migration on familial elder care in rural China. Renming University.

Mason, J. (2004). Managing kinship over long distances: the significance of "The visit". Social Policy \& Society, 3(4), 421-429.

Matthews, S., \& Rosner, T. (1988). Shared filial responsibility: The family as the primary caregiver. Journal of the Marriage and the Family, 50(1), 185-195.

Mazzucato, V. (2007). Transnational reciprocity: Ghanaian migrants and the care of their parents back home. In E. Alber, V. D. Geest\& S. Reynolds (Eds.), Generations in Africa: connections and conflicts (pp. 91-112). Münster: Deutsche National bibliothek. 
McKay, D. (2007). "Sending dollars shows feeling" Emotions and economies in Filipo migration. Mobilities, 2(2), 175-194.

McKibben, C. L. (2010). Between public and private: The transnational community of Sicilians in Monterrey, California. In L. Baldassar (Ed.), Intimacy and Italian migration: Gender and domestic lives in a mobile world (pp. 143-151). Rose Hill: Fordham University Press.

Merla, L. (2010a). Transnational practices of Salvadoran migrants in Australia: an analysis of the factors influencing the capability to care across borders. Lisboa: University of Lisbon.

Merla, L. (2010b). The exchange of care between migrants living in Australia and Belgium and their parents living in El Salvador: a comparative analysis. Lisboa: University of Lisbon/ University of Western Australia.

Mitchell, J. (2007). Ethnography. In W. Outhwaite \& S. Turner (Eds.), The SAGE handbook of social science methodology (pp. 55-66): SAGE Publications.

Montes de Oca, V., Molina, A., \& Avalos, R. (2008). Migración, redes transnacionales y envejecimiento: estudio de las redes familiares transnacionales de la vejez en Guanajuato. México D.F.: Universidad Nacional Autónoma de México/Instituto de Investigaciones Sociales.

Mummert, G. (2010). Growing up and growing old in rural Mexico and China: care-giving for the young and the elderly at the family-state interface. In N. Long, Y. Jingzhong \& W. Yihuan (Eds.), Rural transformations and development- China in context: the everyday lives of policies and people. Northampton: Edward Elgar Publishing.

Núñez, L. (2009). Transnational family life among Peruvian migrants in Chile: Multiple commitments and the role of social remittances. Journal of Comparative Family Studies, 188-204. 
Oral, K. K. (2006). Somos todo aquí y allá: trabajo reproductivo y productivo de mujeres en una comunidad transnacional en Chihuahua, México. Revista de Estudios de Género. La Ventana, 024, 405-437.

Orozco, M. (2006). Transnational families: lives on the edge, but in pursuit of change. Washington: Inter-American Dialogue.

Parreñas, R. (2001). Servants of globalization: Women, migration and domestic work. Stanford: Stanford University Press.

Peñaranda, M. C. (2010). “Te escuchas aquí al lado”. Usos de las tecnologías de la información y comunicación en contextos migratorios transnacionales. Athenea Digital, 19, 239-248.

Pimentel, L. (2006). A prestação de cuidados a pessoas idosas dependentes: Um análise das relações familiares intergeracionais e de germanidade. ISCT Instituto Universitario de Lisboa, Lisboa.

Reynolds, T., \& Zontini, E. (2006). A comparative study of care and provision across Caribean and Italian transnational families. Families \& Social Capital ESRC Research Group Working Paper No. 16. London.

Robles, L. (2003). Género, pobreza y cuidado: La experiencia de mujeres cuidadoras urbanas. In V. Salgado \& R. Wong (Eds.), Envejeciendo en la pobreza. Genero, salud y calidad de vida (1er ed., pp. 123-152). México: Instituto Nacional de Salud Pública.

Robles, L. (2004). El cuidado en el hogar a los enfermos crónicos: Un sistema de autoatención. Cadernos de Saúde Publica, 20(2), 618-625.

Robles, L. (2007). La invisibilidad del cuidado a los enfermos crónicos. Un estudio cualitativo en el barrio de Oblatos. Guadalajara: Editorial Universitaria. Universidad de Guadalajara.

Ryan, L. (2010). Transnational Relations: Family migration among recent Polish migrants in London. International Migration, 49(2), 80-103. 
Senyurekli, A. R. (2007). Caring from a distance: How Turkish transnational families maintain intergenerational relationships. University of Minnesota, Minneapolis.

Senyürekli, A. R., \& Detzner, D. F. (2008). Intergenerational relationships in a transnational context: the case of Turkish families. Family Relations, 57, 457-467.

Solé, C. (2007). Los vínculos económicos y familiares transnacionales: Los inmigrantes ecuatorianos y peruanos en España. Bilbao: Fundación Banco Bilbao Vizcaya.

Van der Geest, S., Mul, A., \&Vermeulen, H. (2004). Linkages between migration and the care of frail older people: observations from Greece, Ghana and The Netherlands. Ageing \& Society, 24, 431-450.

Voigt-Graf, C. (2008). Migration and transnational families in Fiji: comparing two ethnic groups. International Migration 46(4), 15-40.

Wall, K., Nunes, C., \& Matias, A. R. (2008). Mulheres imigrantes e novas trajectórias de migração: um croché transnacional de serviços e cuidados no feminino. In M. Cabral (Ed.), Itinerários: a investigação nos 25 anos do Instituto do Ciencias Sociais (pp. 603-622). Lisboa: Instituto do Ciencias Sociais - Imprensa de Ciências Sociais.

Wilding, R. (2006). "Virtual" intimacies? Families communicating across transnational contexts. Global Networks, 6(2), 125-142.

Wilding, R., \& Baldassar, L. (2009). Transnational family-work balance: Experiences of Australian migrants caring for ageing parents and young children across distance and borders. Journal of Family Studies, 15(2), 177-187.

Wolff, F. C., \& Dimova, R. (2005). How do migrants care for their eldelry parents? Time, money, and location. Swiss Journal of Economics and Statistics, 142, 123-130.

Zechner, M. (2007). Care of older persons in transnational settings. Journal of Aging Studies, 22 (2008), 32-44. 
Zimmer, Z., Korinek, K., Knodel \& Chayovan, N. (2008) Migrant interactions with elderly parents in rural Cambodia and Thailand. Journal of Marriage and Family, 70 (3), 585598.

Zontini, E. (2004). Immigrant women in Barcelona: Coping with the consequences of transnational lives. Journal of Ethnic and Migration Studies, 30(6), 1469-9451.

Zontini, E. (2006). Italian families and social capital. Care provision in a transnational world. Community, Work and Family, 9(3), 325-345.

Zontini, E. (2007). Continuity and change in transnational Italian families: The caring practices of second-generation women. Journal of Ethnic and Migration Studies, 33(7), 1103-1119.

Zontini, E., \& Reynolds, T. (2007). Ethnicity, families and social capital: caring relationships across Italian and Caribbean transnational families. International Review of Sociology, $17(2), 257-277$. 


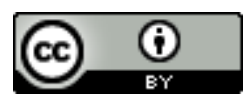

Este texto está protegido por una licencia CreativeCommons 4.0.

Usted es libre para Compartir - copiar y redistribuir el material en cualquier medio o formato- y Adaptar el documen- to remezclar, transformar y crear a partir del material- para cualquier propósito, incluso comercialmente, siempre que cumpla la condición de:

Atribución: Usted debe reconocer el crédito de una obra de manera adecuada, proporcionar un enlace a la licencia, e in- dicar si se han realizado cambios. Puede hacerlo en cualquier forma razonable, pero no de forma tal que sugiera que tie- ne el apoyo del licenciante o lo recibe por el uso que hace. 